\title{
Quality of life of people with dementia in nursing homes in Austria: A cross-sectional study
}

\author{
Daniela Deufert; Karoline Schermann \\ Department of Nursing Science and Gerontology, UMIT - University for Health sciences, Medical informatics and Technology, \\ Hall in Tyrol, Austria
}

Received: November 28, 2016

Accepted: January 4, 2017

Online Published: January 20, 2017

DOI: $10.5430 /$ ijh.v3n1p34

URL: http://dx.doi.org/10.5430/ijh.v3n1p34

\begin{abstract}
Background: The preservation and promotion of the quality of life $(\mathrm{QoL})$ is a central objective in the provision of nursing care for people with dementia $(\mathrm{PwD})$. Long-term care facilities face the major challenge to promote the $\mathrm{QoL}$ of the ever-growing group of PwD by providing adequate nursing care.

Objective: The aim of the study was to outline the QoL of residents with dementia in Austrian nursing homes.

Methods: A cross-sectional study was carried out. The data were collected through the Quality of Life in Dementia Questionnaire (QUALIDEM) and the Functional Assessment Staging Test (FAST).

Results: 147 people with mild to moderately severe dementia and 80 people with severe dementia residing in 23 nursing homes were included in the study. In people with mild to severe dementia, the highest scores were observed in the QUALIDEM-subscales positive affect and feeling at home, indicating a high QoL in these areas. The lowest scores with respect to the QoL were found in the categories restless tense behavior and having something to do. People with a very severe dementia had the lowest scores in the QUALIDEM-subscales social relations, restless tense behavior and having something to do, indicating a low QoL in these areas. The categories with the highest scores were positive self-image and feeling at home.

Conclusion: The results of the study provide first data and clues for possible developments or necessary changes in the care of PwD in long-term care facilities in Tyrol/Austria.
\end{abstract}

Key Words: Dementia, Quality of life, QUALIDEM, Nursing home, Austria

\section{INTRODUCTION}

Dementia diseases are among the most common progressive psychiatric diseases in higher age. ${ }^{[1,2]}$ The prevalence of dementia diseases has been found to increase with age. According to Alzheimer's Disease International, in 2015, 46.8 million people worldwide suffered from Alzheimer's disease. ${ }^{[3]}$

It is now estimated that in Austria currently approximately 130,000 people live with dementia. Due to the increasing age of the population, the number of people with dementia
(PwD) will double until the year 2050 and thus the need for assistance and care will rise further. ${ }^{[4]}$ This expected significant increase of PwD will confront society with increasing challenges with regard to medical and nursing care in the years to come.

Due to the disease's progression, dementia is the most common reason for admission to a long-term care facility. ${ }^{[5,6]}$ Also in Austria, dementia-type illnesses are the most common reason (approximately 43\%) for nursing home admissions. ${ }^{[7]}$ At the moment, approximately 47,000 PwD live in

\footnotetext{
*Correspondence: Daniela Deufert, Assistant Professor; Email: daniela.deufert@ umit.at; Address: Department of Nursing Science and Gerontology, UMIT - University for Health sciences, Medical informatics and Technology, Eduard Wallnoefer-Zentrum 1, 6060 Hall in Tyrol, Austria.
} 
nursing homes (NH) in Austria. Caring for PwD is a very complex task as there is no cure for this type of progressive disease, only the possibility of slowing its progression. As a consequence of dementia, independence and autonomy in day-to-day life as well as the preservation of the emotional well-being becomes a major challenge for the affected. In this context, not the medical therapy but the way how the $\mathrm{PwD}$ are being cared for and how they are treated is a key factor that determines how the PwD experience everyday life and how they feel. A key objective in the care of PwD is the preservation and promotion of the quality of life (QoL). ${ }^{[8-10]}$

The QoL became a key concept in the last few years, especially in context with chronic diseases like dementia. There is, however, no uniform definition for quality of life of people with dementia and also the conceptualization varies. ${ }^{[11-13]}$ QoL is being referred as a multidimensional concept, whereby physical, mental and social well-being are regarded core dimensions of the QoL of PwD. ${ }^{[14-17]}$

Long-term care facilities face the major challenge of supporting the $\mathrm{QoL}$ of a continuously growing group of $\mathrm{PwD}$ by providing adequate care. Additionally, the $\mathrm{QoL}$ is gaining increasing importance as quality indicator in the long term care of elderly people. ${ }^{[18,19]}$

Many PwD enter the NH at a mid-to-late stage, when caring for them at home is no longer possible. ${ }^{[20]}$ Main reasons for this are the increase in care dependency of the PwD on the one hand, ${ }^{[21]}$ and the appearance of behavioral and psychological symptoms of dementia (BPSD) on the other hand. ${ }^{[22]}$ In an advanced stage of the disease cognitive impairments occur which often result in overall care dependency as well as the need for 24-hour supervision. ${ }^{[23]}$ Therefore, people with a severe level of dementia form the major part of the residents with dementia. ${ }^{[20]}$

When we assess the QoL of PwD, we have to differentiate between the single stages of the disease. People with a mild to moderately severe dementia are still able to provide information concerning their QoL. ${ }^{[24]}$ People in an advanced stage of dementia are often no longer able to adequately and reliably provide information concerning their QoL. For PwD it is becoming increasingly difficult to tell what makes a "good life". ${ }^{[25]}$ In the course of a dementia disease, different aspects of life are of particular significance for the individual QoL. In the early stages of dementia, the QoL of PwD is often affected by deficits in organizing everyday life or in independent living. ${ }^{[8,10]}$ Over the course of the disease the independence in activities of daily living decreases continuously. ${ }^{[26]}$ Thus, factors which affect independence, like for example dressing, are no longer as relevant in the stage of mild dementia as in the early stages of the disease. In the late stages of dementia, the affected are normally totally dependent on the help of others. Although in this stage people often develop disorientation, loss of mobility and challenging behavior, every affected experiences dementia in an individual way and requires continuous adjustments of care. ${ }^{[27]}$

There are several international studies on the QoL of PwD which have been conducted in NH's or residential institutions. ${ }^{\left[{ }^{8,28-30]}\right.}$ In Austria, there is still very little research on the QoL of PwD in long-term care facilities. The aim of the study was to present first data on the QoL of residents in Austrian NH's with mild to severe as well as very severe dementia.

\section{METHODS}

A cross-sectional observational study was conducted to examine the QoL of PwD. Twenty-three NHs in Tyrol, Austria, were invited to participate in the study. The chosen NHs are a convenience sample, drawn from 89 Tyrolean residential institutions. A random selection of institutions was not possible due to the resource requirements of the NHs for participating in the study. Potential study participants were screened by nurses working at the participating NHs based on defined criteria. The inclusion criteria for the residents were: living in the $\mathrm{NH}$ for at least four weeks, documented diagnosis of dementia or Mini Mental State Examination (MMSE) $\leq 24$ points. ${ }^{[31]}$ Exclusion criteria were other mental or behavior disorders not based on dementia.

\subsection{Data collection}

Data were collected from November 2013 until July 2015 using a convenience sample of 227 residents. The data were assessed by the caregivers (registered nurses and nursing aids) at the NHs together with study assistants, which were trained in the assessment instruments QUALIDEM and FAST. It was essential that the caregivers knew the resident well and had to be able to evaluate the situation of the resident during the last two weeks retrospectively. The items of the instruments were read aloud to the caregivers by the study assistants and the answers were documented directly.

Gender, age and length of stay in the $\mathrm{NH}$ were assessed via the nursing documentation (medical report) system. For the description of residents' need of care, the levels defined by the Austrian care allowance system were used (with levels ranging from 1 to 7). Thus, need of care is determined by the specific amount of personal care and assistance required by the care dependent person. In order to allocate people to one of the seven care levels, the time allotted monthly to care and assistance needs is assessed. Basically, care level 1 requires a minimum need of 65 hours of care per month. ${ }^{[32]}$ 


\subsubsection{Quality of life}

The QoL was assessed using the German version of the Quality of Life in Dementia Questionnaire (QUALIDEM), a proxy-rated dementia-specific instrument which is specifically designed for institutionalized residents with dementia. ${ }^{[13,33]}$ Through external assessment (proxy-rater) behavior is assessed and the QoL is illustrated on a multidimensional scale. QUALIDEM has two versions. The 37-item version is used to assess the QoL in people with mild to moderately severe dementia, with nine subscales describing the QoL: care relationship, positive affect, negative affect, restless tense behavior, positive self-image, social relationship, social isolation, feeling at home and having something to do. The four response options are: never, rarely, sometimes and frequently. The subscale sum scores were calculated separately and were linearly transformed to values between 0 and 100 . A higher score indicates a better QoL. The three domains positive selfimage, feeling at home and having something to do cannot be assessed in people with severe to very severe dementia. ${ }^{[26,34]}$ Thus, the 18-item version has 6 subscales and is used to assess the QoL of people with severe dementia. The German version of the QUALIDEM showed good psychometric properties. The subscales for both versions showed a moderate to high internal consistency. The Cronbach's $\alpha$ value ranged between 0.64 and 0.87 in the 37-item version and between 0.61 and 0.83 in the 18 -item version. ${ }^{[19]}$ The results for the intra-rater reliability show a high correlation $(r \geq 0.70)$ for all subscales. The weighted kappa value ranged between 0.52 and 0.77 in the 37-item version and between 0.24 and 0.69 in the 18 -item version. ${ }^{[34]}$

\subsubsection{Severity of dementia}

The level of dementia was assessed using the Functional Assessment Staging Test (FAST). ${ }^{[35,36]}$ The FAST was developed for use with Alzheimer's disease (AD) patients to stage a patient's level of disability with respect to AD. The FAST is derived from Axis $\mathrm{V}$ of the Brief Cognitive Rating Scale (BCRS), which itself is derived from the Global Deterioration Scale (GDS) ${ }^{[37]}$ The stages of dementia as defined by FAST are: Stage 1: normal aging, Stage 2: possible mild cognitive impairment, Stage 3: mild cognitive impairment, Stage 4-6: mild to moderately severe dementia and Stage 7: severe dementia ${ }^{[36,38]}$

The coefficient of scalability of the FAST was reported to be $0.98 .{ }^{[39]}$ Rater consistency and rater agreement were calculated using the intraclass correlation coefficient (ICC); excellent reliability was reported (fixed effect $\mathrm{ICC}=0.86$; random effect $\mathrm{ICC}=0.87) .{ }^{[39]}$

Although currently there are no data available on the testtheoretical quality criteria of the German version of FAST, it has already been used in previous studies. ${ }^{[13,34]}$ Due to 36 the comparability with these studies we also chose FAST as instrument for assessing the degree of dementia.

\subsection{Statistical analysis}

The data were analyzed with SPSS for Windows Version 20.0 (IBM SPSS Inc., Chicago, IL). Results are presented as Mean $(\mathrm{M}), \pm$ Standard Deviation (SD) or as number $(\mathrm{N})$ and percentage (\%). Between groups, comparisons were tested for statistical significance via the $\chi^{2}$ test for categorical variables and via the Mann-Whitney U-test or Student's t-test for continuous variables as appropriate. Statistical significance was established at $p<.05$.

\subsection{Ethical consideration}

This study was approved by the Research Committee for Scientific and Ethical Questions (RCSEQ) of UMIT - University for Health Sciences, Medical Informatics and Technology, Hall in Tyrol. The participants and/or their relatives and legal representatives were informed about the study and gave their written consent.

\section{RESUlts}

\subsection{Sample characteristics}

A total of 236 residents participated in the study. Based on the severity of dementia, the sample was divided into two sub-samples, namely people with mild to moderately severe dementia (FAST 4-6) and people with severe dementia (FAST 7). The data of nine participants had to be excluded from further data evaluation as they were tested FAST 1-3.

Table 1 lists the demographic characteristics of the study population. Most of the participants in both groups were female and the average age was 84.7 years in the FAST 4-6 group and 82 years in the FAST 7 group. The length of stay in the nursing home was higher in the FAST 7 group (4.3 vs. $3.1 ; p=.007)$, as well as the level of care need (4.1 vs. 5.4; $p=.000)$.

\subsection{Quality of life}

For the QoL assessment of people with severe cognitive decline (FAST = 7), the 18 item-version of QUALIDEM was used. ${ }^{[28]}$ The QUALIDEM results of people with mild to moderately severe dementia (FAST 4-6) and severe dementia (FAST 7) are illustrated in Table 2. The results showed QoL subscale scores ranging from 42.2 (subscale social relations) to 77.0 (subscale positive affect).

People with mild to moderately severe dementia (FAST 4-6) had the highest scores in the domains positive affect, feeling at home and social isolation. They had lower mean scores and thus a lower QoL in the domains something to do and restless tense behavior.

ISSN 2377-7338 E-ISSN 2377-7346 
Table 1. Characteristics of the study sample

\begin{tabular}{llll}
\hline & $\begin{array}{l}\text { FAST 4-6 } \\
(\boldsymbol{N}=\mathbf{1 4 7})\end{array}$ & $\begin{array}{l}\text { FAST 7 } \\
(\boldsymbol{N}=\mathbf{8 0})\end{array}$ & $\boldsymbol{p}$-value \\
\hline Age (years), Mean $( \pm S D$; range) & $84.7( \pm 7.8 ; 55-97)$ & $82.0(10.8 ; 44-101)$ & $.03^{\S}$ \\
Gender (female), $N(\%)$ & $112(76.2)$ & $64(80.0)$ & $.51^{\#}$ \\
MMSE value, Mean $( \pm S D)$ & $15.9(6.2)$ & $7.8(7.2)$ & $.000^{\S}$ \\
Missing N (\%) & $30(20.4)$ & $29(36.2)$ & \\
Level of care need", $N(\%)$ & & & \\
None & $2(1.4)$ & 0 & \\
1 & $1(0.7)$ & 0 & \\
2 & $11(7.5)$ & 0 & \\
3 & $31(21.1)$ & $5(6.3)$ & \\
4 & $43(29.3)$ & $3(3.8)$ & $.000^{\S}$ \\
5 & $40(27.2)$ & $33(41.3)$ & $.007^{\S}$ \\
6 & $19(12.9)$ & $34(42.5)$ & $5(6.3)$ \\
7 & 0 & $5.4(0.9)$ & \\
\hline
\end{tabular}

Note. ${ }^{*}$ According to the Austrian levels of care allowance; Level of care need, Level $1=65$ hours/monthly - Level $7=180$ hours/monthly; ${ }^{\circledR}$-test; ${ }^{*} \chi^{2}$-test

Residents with a FAST 7 score reached the highest scores in the domains social isolation, care relationship and positive affect. This group had the lowest QoL in the domains social relations, restless tense behavior and negative affect.

A comparison of the two groups showed that people with mild to moderately severe dementia had higher QoL scores in all QUALIDEM categories. Statistically significant differences were observed in the QUALIDEM categories positive affect $(p=.000)$, restless tense behavior $(p=.000)$ and social relations $(p=.000$ ) (see Table 2). Also the QUALIDEM total score was statistically significantly higher in the FAST 4-6 group $(p=.000)$.

Table 2. Quality of life according to the degree of dementia severity

\begin{tabular}{llll}
\hline QUALIDEM Subscales $^{\S}$ & $\begin{array}{l}\text { FAST 4-6 } \\
\text { Mean (SD) }\end{array}$ & $\begin{array}{l}\text { FAST 7 } \\
\text { Mean (SD) }\end{array}$ & p-value $^{\# \#}$ \\
\hline Care relationship & $70.6(23.5)$ & $66.7(23.1)$ & .233 \\
Positive affect & $77.0(21.1)$ & $62.2(27.2)$ & $.000^{* *}$ \\
Negative affect & $65.4(25.9)$ & $61.3(22.7)$ & .233 \\
Restless tense behavior & $59.4(31.0)$ & $42.5(33.1)$ & $.000^{* *}$ \\
Positive self-image & $73.1(27.2)$ & & $.000^{* *}$ \\
Social relations & $62.4(18.5)$ & $42.2(20.4)$ & .294 \\
Social isolation & $75.0(21.7)$ & $71.5(27.0)$ & \\
Feeling at home & $75.6(22.4)$ & & $.000^{* *}$ \\
Something to do & $45.3(29.8)$ & $68.9(15.2)$ & \\
Total score & $78.2(15.3)$ & & \\
\hline
\end{tabular}

Note. ${ }^{\# \#}$ t-test; ${ }^{*} p<.05 ;{ }^{* *} p<.001 ;{ }^{\S}$ higher score (maximum value $=100$ ) indicate better QoL; ${ }^{\#}$ cannot be assessed in people with severe dementia

\subsection{Behavior of the PwD}

The three most frequently observed positive behaviors in the group with mild to moderately severe dementia were responds positively when approached, feels at ease in company of others and is in a good mood. Is restless, is sad and is angry were the most frequently observed negative behaviors in this group. The most frequently observed positive behav- iors in the group with severe dementia were mood can be influenced in a positive sense, has a contented appearance and is in a good mood. The three most frequently observed negative behaviors in this group were makes restless movements, is restless and has tense body language (see Table 3). 
Table 3. Behavior of the PwD according to the degree of dementia severity

\begin{tabular}{|c|c|c|}
\hline QUALIDEM Subscales and Items & $\begin{array}{l}\text { FAST 4-6 } \\
\%(N)^{*}\end{array}$ & $\begin{array}{l}\text { FAST } 7 \\
\%(N)^{*}\end{array}$ \\
\hline \multicolumn{3}{|l|}{ Care relationship } \\
\hline Rejects help from nursing assistants ${ }^{* *}$ & $32.1(44)$ & ----- \\
\hline Is angry & $42.9(63)$ & $41.6(32)$ \\
\hline Has conflicts with nursing assistants & $24.5(36)$ & $25.7(20)$ \\
\hline Accuses others ${ }^{* *}$ & $34.3(47)$ & ------ \\
\hline Appreciates help that he or she receives ${ }^{* *}$ & $15.0(22)$ & ----- \\
\hline Accepts help & $5.1(7)$ & $9.8(7)$ \\
\hline Criticizes the daily routine $^{* * *}$ & $17.5(24)$ & ----- \\
\hline \multicolumn{3}{|l|}{ Positive affect } \\
\hline Is cheerful $^{* *}$ & $82.5(113)$ & ----- \\
\hline Has a contented appearance & $88.5(130)$ & $77.261)$ \\
\hline Is capable of enjoying things in daily life ${ }^{* *}$ & $89.1(131)$ & ------ \\
\hline Is in a good mood & $89.8(132)$ & $71.1(54)$ \\
\hline Has a smile around the mouth & $81.0(111)$ & $68.1(49)$ \\
\hline Mood can be influenced in a positive sense & $87.0(128)$ & $79.5(62)$ \\
\hline \multicolumn{3}{|l|}{ Negative affect } \\
\hline Makes an anxious impression & $32.7(48)$ & $43.6(34)$ \\
\hline Is $\operatorname{sad}^{* *}$ & $40.1(55)$ & ----- \\
\hline Cries & $17.0(27)$ & $16.3(13)$ \\
\hline \multicolumn{3}{|l|}{ Restless tense behavior } \\
\hline Makes restless movements & $39.4(58)$ & $56.3(45)$ \\
\hline Is restless & $43.5(64)$ & $56.3(45)$ \\
\hline Has tense body language & $36.1(53)$ & $63.8(51)$ \\
\hline \multicolumn{3}{|l|}{ Positive self-image } \\
\hline Indicates he or she would like more help ${ }^{* * *}$ & $19.0(26)$ & ------ \\
\hline Indicates not being able to do anything ${ }^{* *}$ & $31.3(43)$ & ----- \\
\hline Indicates feeling worthless $^{* *}$ & $26.3(36)$ & ------ \\
\hline \multicolumn{3}{|l|}{ Social relations } \\
\hline Has contact with other residents & $85.7(126)$ & $43.8(35)$ \\
\hline Responds positively when approached & $97.2(143)$ & $85.1(68)$ \\
\hline Takes care of other residents ${ }^{* * *}$ & $35.0(48)$ & ----- \\
\hline Cuts oneself off from environment & $68.0(100)$ & $76.3(58)$ \\
\hline Is on friendly terms with one or more residents ${ }^{* *}$ & $64.3(88)$ & ------ \\
\hline Feels at ease in company of others ${ }^{* *}$ & $89.9(123)$ & ------ \\
\hline \multicolumn{3}{|l|}{ Social isolation } \\
\hline Is rejected by other residents & $28.5(42)$ & $26.3(21)$ \\
\hline Openly rejects contact with others & $29.2(43)$ & $25.2(20)$ \\
\hline Calls out & $11.6(17)$ & $26.3(21)$ \\
\hline \multicolumn{3}{|l|}{ Feeling at home } \\
\hline Indicates that he or she is bored $^{* *}$ & $73.0(100)$ & ------ \\
\hline Indicates feeling locked up ${ }^{* *}$ & $81.1(111)$ & ----- \\
\hline Feels at home on the ward ${ }^{* *}$ & $85.4(117)$ & ------ \\
\hline Wants to get off the ward** & $72.9(100)$ & ------ \\
\hline \multicolumn{3}{|l|}{ Having something to do } \\
\hline Find things to do without help from others ${ }^{* *}$ & $56.9(78)$ & ------ \\
\hline Enjoys helping with chores on the ward ${ }^{* *}$ & $34.3(47)$ & ----- \\
\hline
\end{tabular}

Note. ${ }^{*}$ Nurses report that resident shows behavior either sometimes or frequently; ${ }^{* *}$ Items cannot be assessed in people with severe dementia (FAST = 7)

\section{Discussion}

Generally, also this study confirmed that people with mild to moderately severe dementia had a better QoL in all domains of the QUALIDEM in comparison to people with severe dementia. ${ }^{[26]}$ People with mild to moderately severe dementia (FAST 4-6) presented the highest QoL results in the domains positive affect, feeling at home and social isolation. A reduced QoL was detected in the domains something to do or restless tense behavior. ${ }^{[39]}$ It seems that keeping people with cognitive decline engaged and stimulated constitutes a major challenge for carers. Especially at the beginning of the disease, the QoL of PwD is affected by the experience 
of a loss of control and behavioral competence. However, in this stage it is possible to maintain the autonomy and thus the QoL of the affected through an efficient use of their resources and activation, whereby the confrontation with their own deficiencies should be avoided as far as possible. This requires appropriate advisory and supervision competencies of the qualified nursing staff. ${ }^{[25]}$

People with severe dementia suffered in particular from impairments in the domains social relations and restless tense behavior, as well as in the domain negative affect just as people with milder dementia. Higher scores and thus a better QoL in the subscales social isolation and positive affect were also detected in people with severe dementia. Previous studies produced the highest scores in the subscale social isolation in people with severe or very severe dementia too. ${ }^{[40,41]}$ Also in our study, people with severe dementia showed increased restless tense behavior. ${ }^{[26,41]}$ It is to be noted that such behavior may influence and reduce the QoL-assessment of PwD. ${ }^{[30]}$ The proxy-rated QoL is often negatively influenced by psychiatric symptoms. ${ }^{[42]}$

PwD living in long term care facilities have the risk of social isolation or loneliness. ${ }^{[43]}$ Taken as a whole, in this study the domain social relations is apparently most affected by the increasing cognitive decline. Nevertheless, Moyle et al. ${ }^{[44]}$ were able to show that social interaction had an essential influence on the QoL of PwD. Also in our study it became obvious that a large majority of people with severe dementia isolated themselves from their environment. This social withdrawal, in particular of PwD in an advanced stage and with more severe cognitive decline, was also detected in earlier studies. ${ }^{[43]}$ It should also be noted that social contacts contribute significantly to cognitive health and have an important influence on the well-being of PwD. ${ }^{[45-47]} \mathrm{PwD}$ need intensive guidance and care which gives them support and stability. Therefore it is necessary that the qualified nurses, on the one hand, encourage the relation between relatives and residents with severe dementia, and, on the other hand, that they themselves maintain the relation. ${ }^{[25]}$ Nursing staff has to be aware of the fact that PwD are vulnerable, particularly to changes in their psychosocial environment, but are not always able to react to these changes adequately. ${ }^{[48]}$ The later stages of the disease are often characterized by limitations in activities of daily living as well as severe cognitive impairments and the appearance of BPSD. Care and support in special care units offers the possibility to maintain the QoL of PwD accordingly ${ }^{[49]}$ and to ease the interaction with
PwD. ${ }^{[25]}$ A dementia-specific environment may serve as therapeutic instrument ${ }^{[50]}$ as well as a means for orientation and promotion of social interaction. ${ }^{[51]}$ Its deficit-compensating effect can help improve the QoL of PwD. ${ }^{[25]}$

However, insufficient QoL of PwD in long-term care facilities is often caused by a lack of staff resources, insufficient training or insufficient social competencies of the carers. ${ }^{[49]}$ Thereby it is necessary that specially trained nurses are sensitive to the individual needs of the PwD to plan and implement appropriate individual measures. The QoL of PwD can be promoted through needs-oriented individual care. ${ }^{[25]}$

Due to its subjective components, the QoL, if possible, should be assessed by means of patient self-reports. ${ }^{[52]}$ Despite their progressive cognitive decline, it is possible to collect valid data on the QoL in earlier-to-mid stage patients through self-assessment. The reliability of QoL self-reports in later stages of the disease has been questioned. ${ }^{[33]}$ It should be taken into account that the results of proxy measures, like in our study, can be lower and also may differ from the results of self-assessment. ${ }^{[42,54,55]}$

\section{Conclusions}

The results of the study provide first data and clues for possible changes and developments in the care of PwD in longterm care facilities in Austria. The overall QoL of the residents was considered high by the carers, whereby people with severe dementia were deemed to have a lower QoL than people with less cognitive impairments. The experiencing and behavior of PwD depends on their mental, social and physical environment. ${ }^{[25]}$ In order to guarantee the individual adaptation to the needs of PwD and to maintain their QoL, concepts like for example "Understanding Diagnostics"[56] need to be further developed in the future and training programs to encourage independence and the organization of day-to-day life on the one hand, and, on the other hand, to facilitate social relations, have to be extended and intensified in the future as they can have positive effects on the QoL of residents with dementia in Austria.

\section{ACKNOWLEDGEMENTS}

This study was supported by the Tyrolean Science Fund (TWF) (GZ_UNI-0404/1231).

\section{CONFlicts OF InTEREST Disclosure}

The authors have no conflicts of interest to declare for this study. 


\section{REFERENCES}

[1] Fratiglioni L, Launer LJ, Andersen K, et al. Incidence of dementia and major subtypes in Europe: A collaborative study of populationbased cohorts. Neurologic Diseases in the Elderly Research Group. Neurology. 2000; 54(11 Suppl 5): 10-5.

[2] Colantuoni E, Surplus G, Hackman A, et al. Web-based application to project the burden of Alzheimer's disease. Alzheimer's \& Dementia. 2010; 6(5): 425-8. https://doi.org/10.1016/j.jalz.201 0.01 .014

[3] Alzheimer's Disease International. World Alzheimer Report 2015. The global impact of dementia. An analysis of prevalence, incidence, cost and trends. London. [cited 2016 Jul 7]. Available from: https ://www.alz.co.uk/research/world-report-2015.

[4] Höfler S, Bengough T, Winkler P, et al. Österreichischer Demenzbericht 2014. Wien: Bundesministerium für Gesundheit und Sozialministerium, 2015. [cited 2016 May 12]. Available from: http://www.alzheimer-europe.org/Policy-in-Pra ctice2/National-Dementia-Strategies/Austria.

[5] Schoenemakers B, Buntinx F, Devroey D, et al. The process of definitive institutionalization of community dwelling demented vs. non demented elderly: data obtained from a network of sentinel general practicioners. International Journal of Geriatric Psychiatry. 2009; 24: 523 31. PMid: 18942067. https ://doi .org/10.1002/gps . 2147

[6] Luppa M, Luck T, Weyerer S, et al. Prediction of institutionalization in the elderly. A systematic review. Age Ageing. 2010; 39(1): 31-8 PMid: 19934075. https://doi.org/10.1093/ageing/afp202

[7] Gleichweit S, Rossa M. Erster österreichischer Demenzbericht Teil 1: Analyse zur Versorgungssituation durch das CC Integrierte Versorgung der österreichischen Sozialversicherung. Wiener Gebietskrankenkasse. 2009. [cited 2016 Feb 23]. Available from: http: // www . wgkk . at/cdscontent/load? contentid=10008.595154.

[8] Hoe J, Hancock G, Livingston G, et al. Quality of life of peole with dementia in residential care homes. British Journal of Psychiatry. 2006; 188: 460-4. https ://doi.org/10.1192/bjp.bp.104.007658

[9] Moyle W, Mcallister M, Venturato L, et al. Quality of life and dementia. The voice of the person with dementia. Dementia. 2007; 6(2): 175-91. https://doi.org/10.1177/1471301207080362

[10] Beerens HC, Zwakhalen SM, Verbeek H, et al. Factors associated with quality of life of people with dementia in long-term care facilities: a systematic review. International Journal of Nursing Studies. 2013; 50(9): 259-70. https://doi.org/10.1016/j.ijnurstu .2013 .02 .005

[11] Ettema TP, Droes RM, de Lange J, et al. The concept of quality of life in dementia in the different stages of the disease. Int Psychogeriatr. 2005; 17(3): 353-70. PMid: 16252370. https: //doi.org/10.1017/S1041610205002073

[12] Ettema TP, Dröes RM, de Lange J, et al. QUALIDEM: development and evaluation of a dementia specific quality of life instrument - validation. International Journal of Geriatric Psychiatry. 2007; 22(5): 424-30. https : //doi.org/10.1002/gps. 1692

[13] Dichter MN, Halek M, Dortmann O, et al. Measuring the quality of life of people with dementia in nursing homes in Germany - the study protocol for the QOL-Dem Project. GMS Psycho-Social-Medicine. 2013; 10: 1-8. http://dx.doi.org/10.3205/psm000096

[14] Lawton MP. Assessing quality of life in Alzheimer disease research. Alzheimer Disease Associated Disorders, 1997; 11: 91-9. PMid: 9437453.

[15] Brod M, Stewart AL, Sands L, et al. Conceptualization and measurement of quality of life in dementia: the dementia quality of life instrument (DQOL). Gerontologist. 1999; 39: 25-35. PMid: 10028768. https://doi.org/10.1093/geront/39.1.25
[16] Selai C, Trimble MR. Assessing quality of life in dementia. Aging \& Mental Health. 1999; 3: 101-11. https ://doi.org/10.1080/13 607869956253

[17] Dichter M, Schmidhauber M. The concept of quality of life of people with dementia - Two approaches for a theoretical discussion. Pflege \& Gesellschaft. 2016; 21(2): 114-29.

[18] Porzsolt F, Kojer M, Schmidl M, et al. A new instrument to describe indicators of well-being in old-old patients with severe dementia - the Vienna List. Health and Quality of Life Outcomes. 2004. https : //doi .org/10.1186/1477-7525-2-10

[19] Dichter M, Bartholomeyczik S, Nordheim J, et al. Validity, reliability and feasibility of a quality of life questionnaire for people with dementia. Zeitschrift für Gerontologie und Geriatrie. 2011; 44: 405-10. https://doi.org/10.1007/s00391-011-0235-9

[20] Alzheimervereinigung Schweiz. Leben mit Demenz in der Schweiz. Zahlen zur Demenz. Yverdon-les-Bains. 2012. [cited 2016 Apr 10]. Available from: http://server25.hostpoint.ch/ alzch1/al z.ch/index.php/zahlen-zur-demenz.html

[21] Bavazzo A, Magnolfi D, Calvani D, et al. Functional evaluation of Alzheimer patients during clinical trials: a review. Archives of Gerontology and Geriatrics. 2003; 26: 27-32. https ://doi.org/10.1 016/S0167-4943(98)80005-8

[22] IPA (International Psychogeriatric Association). Behavioral and Psychological Symptoms of Dementia (BPSD) Educational Pack. 2002. [cited 2016 Dec 17] Available from: http://www.alzheimer.me d. br/ipa.pdf.

[23] Weyerer S. Altersdemenz. Gesundheitsberichterstattung des Bundes. 28, Berlin: Robert-Koch Institut, 2005. PMid: 15868346.

[24] Moyle W, Murfield JE, Griffiths SG, et al. Assessing quality of life of older people with dementia: a comparison of quantitative self-report and proxy account. Journal of Advanced Nursing. 2012; 68(10): 2237-46. http://dx . doi .org/10.1111/j.1365-2648. 2011.05912

[25] Oppikofer S. Lebensqualität von Menschen mit einer Demenzerkrankung. University of Zurich. 2013 [cited 2016 Apr 10]. Available from: https://www.bag.admin.ch/themen/gesundheit spolitik/13916/15495/index.html.

[26] Wetzels RB, Zuidema SU, de Jonghe JFM, et al. Determinants of Quality of Life in Nursing Home Residents with Dementia Dementia and Geriatric Cognitive Disorders. 2010; 29: 189-97. https://doi .org/10.1159/000280437

[27] Volicer L. Goals of care in advanced dementia: Comfort, dignitiy and psychological well-being. American Journal of Alzheimer's Disease. 1997; 12(5): 196-7. https://doi.org/10.1177/153331759701 200502

[28] Selwood A, Thorgrimsen L, Orrell M. Quality of life in dementia - a one year follow-up study. International Journal of Geriatric Psychiatry. 2005; 20(3): 232-7. PMid: 15717339. https : //doi.org/10.1002/gps.1271

[29] Sloane PD, Zimmerman S, Reed PS, et al. Evaluation the quality of life of long-term care residents. The Gerontologist. 2005; 45(1): 37-49. PMid: 16230748. https://doi.org/10.1093/geront/4 5. suppl_1.37

[30] Abrahamson K, Clark D, Perkins A, et al. Does Cognitive Impairment Influence Quality of Life Among Nursing Home Residents? The Gerontologist. 2012; 52(5): 632-40. https ://doi .org/10.1 093/geront/gnr137

[31] Folstein MF, Folstein SE, McHugh PR. Mini-Mental State. A practical method for grading the cognitive state of patients for the clinician. Journal of Psychiatirc Research. 1975; 44: 93-106.

[32] RIS. Federal Law Gazette $110 / 1993$ in its current version. 2016. [cited 2016 May 25]. Available from: 
https://www.ris.bka.gv.at/GeltendeFassung.wxe? Abf rage=Bundesnormen\&Gesetzesnummer $=10008859$.

[33] Ettema TP, Dröes RM, De Lange J, et al. QUALIDEM: Development of a Dementia-specific Quality of Life Instrument. Scalability, reliability and internal structure. International Journal of Geriatric Psychiatry. 2007; 22: 549-56. https://doi .org/10.1002/gps. 1713

[34] Dichter MN, Schwab CG, Meyer G, et al. Measuring the quality of life in mild to very severe demtia: Testing the inter-rater and intra-rater reliability of the German version on the QUALIDEM. International Psychogeriatrics. 2014; 26(5): 825-36. https : //doi.org/10.1017/S1041610214000052

[35] Reisberg B. Functional Assessment Staging (FAST). Psychopharmacology Bulletin. 1988; 24: 653-659. PMid: 3249767.

[36] Reisberg B, Ferris SH. Brief Cognitive Rating Scale (BCRS). Psychopharmacology Bulletin. 1988; 24: 629-33. PMid: 3249764.

[37] Leon de MJ, Reisberg B. An Atlas of Alzheimer's Disease. The Encyclopedia of Visual Medicine Series. Parthenon Publishing, Carnforth, 1999. [cited 2016 Jul 2]. Available from: http://www. dementia carecentral.com/aboutdementia/facts/stages.

[38] Sclan SG, Reisberg B. Functional Assesment Staging (FAST) in Alzheimer's disease: reliability, validity and ordinality. International Psychogeriatrics. 1992; 4(1): 55-69. PMid: 1504288. https : //doi.org/10.1017/S1041610292001157

[39] Gräske J, Meyer S, Worch A, et al. Family visits in shared-housing quality of life. BMC Geriatrics. 2015; 15: 14. https://doi.org/ $10.1186 / \mathrm{s} 12877-015-0012-5$

[40] Koopmanns RTCM, van der Molen M, Raats M, et al. Neuropsychiatric symptoms and quality of life in patients in the final phase of dementia. International Journal of Geriatric Psychiatry. 2009; 24: 25-32. https://doi.org/10.1002/gps. 2040

[41] Wolf-Ostermann K, Worch A. DeWeGe-Berliner Studie zur outcombezogenen Evaluation der gesundheitlichen Versorgung von Menschen mit Demenz in ambulant betreuten Wohngemeinschaften. Berlin: Bundesministerium für Gesundheit. 2011. [cited 2016 Jul 2]. Available from: https://www. wegweiser-demenz.de/fileadmin/de.wegw eiser-demenz/content.de/downloads/10_informatione n_fuer_Fachkraefte/Projektbericht_DeWeGE_TN.pdf.

[42] Hoe J, Katana C, Orrell M, et al. Quality of life in dementia: care recipient and caregiver perceptions of quality of life in dementia: the LASER-AD study. International Journal of Geriatric Psychiatry. 2007; 22: 1031-6. PMid: 17380488. https://doi.org/10.1002/ gps. 1786

[43] Moyle W, Kellett U, Ballantyne A, et al. Dementia and loneliness: an Australian perspective. Journal of Clinical Nursing. 2011; 20: 1445-53. http://dx.doi.org/10.1111/j.1365-2702.2010.0 3549.

[44] Moyle W, Fetherstonhaugh D, Greben M, et al. Influencers on quality of life with dementia in long-term care: a descriptive exploratiy approach. BMC Geriatrics. 2015; 15: 50. http://dx.doi .org/1 $0.1186 / \mathrm{s} 12877-015-0050-z$.

[45] Butler RN, Forette F, Greengross BS. Maintaining cognitive health in an ageing society. The Journal of the Royal Society for the Promotion of Health. 2004; 124(3): 110-21. https ://doi .org/10.1177/14 6642400412400312
[46] Krueger KR, Wilson RS, Kamenetsky JM, et al. Social engagement and cognitive function in old age. Experimental aging research. 2009; 35(1): 45-60. https://doi.org/10.1080/0361073080254502 8

[47] Zuidema S, Koopmanns R, Verhey F. Prevalence and predictors of neuropsychiatric symptoms in cognitively impaired nursing home patient. Journal of Geriatric Psychiatry and Neurology. 2007; 20(1): 41-9. PMid: 17341770. https://doi.org/10.1177/08919887 06292762

[48] Becker S, Kruse A, Schröder J, et al. Das Heidelberger Instrument zur Erfassung von Lebensqualität bei Demenz (H.I.L.DE). Dimensionen von Lebensqualität und deren Operationalisierung. Zeitschrift für Gerontologie und Geriatrie. 2005; 38: 108-21. PMid: 15868349 https://doi.org/10.1007/s00391-005-0297-7

[49] Cahill S, O'Shea E, Pierce M. Creating Excellence in Demenita Car. A research review for Irland's National Dementia Strategy. The School of Social Work and Social Policy, Trinity College, Dublin and The Irish Centre for Social Gerontology, NUIG. January 25, 2012. [cited $2016 \mathrm{Jul}$ 5]. Available from: http://www .atlantic philanthropies.org/research-reports/report-creatin g-excellence-dementia-care-research-review

[50] Marshall M. What do Service Planners and Policy-Makers Need from Research? International Journal of Geriatric Psychiatry. 1999; 14(2): 86-96. https://doi.org/10.1002/(SICI) 1099-1 166 (199902) $14: 2<86:$ : AID-GPS940>3.0.CO;2-3

[51] Day K, Carreon D, Stump C. Therapeutic design of environments for people with dementia: a review of empirical research. The Gerontologist. 2000; 40: 397-416. PMid: 10961029. https ://doi.org/10 $.1093 /$ geront/40.4.397

[52] Logsdon RG, Gibbons LE, McCurry SM, et al. Assessing Quality of Life in older adults with cognitive impairment. Psychosomatic Medicine. 2002; 64: 510-9. PMid: 12021425. https://doi.org/ 10.1097/00006842-200205000-00016

[53] Bédard M, Molloy DW, Squire L, et al. Validity of self-reports in dementing research: The geriatric Depression Scale. Clinical Gerontologist. 2003; 26: 155-63. https://doi.org/10.1300/J018v2 $6 \mathrm{n} 03$ _13

[54] Nakanishi K, Hanihara T, Mutai H, et al. Evaluating the quality of life of people with dementia in residential care facilities. Dementia and Geriatric Cognitive Disorders. 2011; 32(1): 39-44. https://doi.org/10.1159/000329443

[55] Graeske J, Meyer S, Wolf-Ostermann K. Quality of life ratings in dementia care a cross-sectinal study to identify factors associates with proxy-ratings. Health and Quality of Life Outcomes. 2014; 12: 177. https://doi .org/10.1186/s12955-014-0177-1

[56] Bartholomeyczik S, Halek M, Sowinski C, et al. Rahmenempfehlungen zum Umgang mit herausforderndem Verhalten bei Menschen mit Demenz in der stationären Altenhilfe. Berlin: Bundesministerium für Gesundheit. 2006. [cited 2016 Jul 2]. Available from: https://www. bundesgesundheitsministerium.de/filead min/Dateien/Publikationen/Pflege/Berichte/Bericht_ Rahmenempfehlungen_zum_Umgang_mit_herausforderndem _Verhalten_bei_Menschen_mit_Demenz_in_der_stationa eren_Altenhilfe.pdf 